International Journal of Engineering \& Technology, $7(3.7)(2018) 167-170$
International Journal of Engineering \& Technology
SPC
Website: www.sciencepubco.com/index.php/IJET
Research paper

\title{
Effect of the Dietary Fat Sources on Performance, Liver Fatty Acid Composition and Meat Cholesterol Content in Broiler
}

\author{
Jannatara. Khatun ${ }^{1,4}$, Teck Chwen Loh ${ }^{1,2 *}$, Henny Akit1, Hooi Ling Foo ${ }^{2,3}$, Rosfarizan Mohammad ${ }^{2}$ \\ ${ }^{1}$ Department of Animal Science, Faculty of Agriculture, ${ }^{2}$ Department of Bioprocess Technology, \\ Faculty of Biotechnology and Biomolecular Sciences, and, ${ }^{3}$ Institute of Bioscience, \\ Universiti Putra Malaysia, Selangor, Malaysia; and ${ }^{4}$ Department of Animal Science and Nutrition, \\ Chittagong Veterinary and Animal Sciences University, Chittagong, Bangladesh \\ *Corresponding authorE-mail: tcloh@upm.edu.my
}

\begin{abstract}
A study was conducted to evaluate the effect of feeding diet containing palm oil (PO) and sunflower oil (SO) and their combination on bird performance, liver fatty acid profile and meat cholesterol content of broiler. A total of 144 day-old broiler chicks (Cobb) randomly assigned into four dietary treatments and fed for six weeks. The dietary treatments were T1, 6\% PO (control); T2, 4\% PO + $2 \% \mathrm{SO} ; \mathrm{T} 3,2 \% \mathrm{PO}+4 \% \mathrm{SO}$; and $\mathrm{T} 4,6 \% \mathrm{SO}$. The body weight gain increased and feed conversion ratio (FCR) reduced with the increasing level of unsaturated fatty acid sources oil (SO) compared to control group (PO). Significantly higher $(\mathrm{P}<0.05)$ overall daily body weight gain and lower FCR were found in broilers fed dietary treatments T3 compared to other treatments. However, no differences $(\mathrm{P}<0.05)$ were found in daily body weight gain and FCR among the two combination of oil and SO alone. Dietary treatments influence the fatty acid composition of liver and increasing the dietary SO decreased the level of C16:0, C18:0, C18:1n-9, SFA and MUFA and increased the C18:2n-6, UFA: PUFA, UFA: SFA and PUFA: SFA. Birds fed PO had higher cholesterol concentration in meat which was decreased by supplementation of SO in broiler diet. However, cholesterol concentration was not differed in meat among the dietary SO and combination of SO and PO. It could be concluded that supplementation of a combination of PO and SO in broiler diet increased performance, altered the fatty acid composition of liver tissue and decreased cholesterol content of meat which may have a favorable impact on consumer's health.
\end{abstract}

Keywords: Broiler; Oil, Growth; Fatty acid; Meat cholesterol

\section{Introduction}

Fats and oils are frequently included to broiler diet for increasing energy to meet the requirements because these are concentrated energy sources and affect growth, feed efficiency, feed dust and diet palatability $[1,2]$. Supplementation of unsaturated fat in broiler diet leads to higher metabolizable energy for its higher solubility (into micelles) and ultimately more digestible in the intestine than saturated fatty acid from animal source or other oils rich in saturated fatty acid (SFA) [1]. In addition, they may act synergistically in the absorption of saturated fatty acids when mixed with unsaturated fats to poultry diets.

In the poultry, the fatty acid composition of tissue lipids and cholesterol content of meat depends on the dietary fatty acids $[3,4]$ and can alter the concentration of lipoproteins and triglycerides (TG) in blood [5]. Usually, dietary fats rich in unsaturated fatty acid (UFA) reduce lipoproteins and TG in blood comparison to saturated fats. So, changes of fatty acid in diet might be reflected in the blood, which in turn would be transported to target organs such as muscle [6] and adipose tissue [2]. The cholesterol content of food especially from meat recently becoming a major concern of consumer's, as higher intake of cholesterol increased the incidence of diseases especially coronary heart diseases $[7,8]$. The liver is a vital organ plays a leading role in synthesis and oxidation of fatty acids [9]. Thus, liver fatty acid composition could provide valuable information on accumulation of fat, TG as well as, cholesterol content in the body. The use of unsaturated fats in chicken diets may reduce cholesterol and improve product quality in terms of fatty acid contents. However, such product is susceptible to oxidative spoilage [10]. In contrast, saturated fats increased the oxidative stability. Supplementation both unsaturated and saturated fats in birds might be an effective approach to increase performance and enhance meat quality of broiler. Thus the current study was conducted to evaluate the effect of feeding diet containing palm oil (rich in SFA) and sunflower oil (rich in UFA) and their combination on bird performance, liver fatty acid profile and meat cholesterol content of broiler.

\section{Materials and Methods}

This study was conducted following the Animal Ethics Guidelines (UPM/IACUC/AUP-R081/2016) of the Research Policy approved by the Universiti Putra Malaysia.

One hundred forty four (144) day-old broiler chicks (Cobb) were purchased from local hatchery of Malaysia. The chicks were individually weighed, wing-banded and randomly allocated into four dietary groups with six replications and each replication comprised of six birds. Broiler chicks were vaccinated against infectious bronchitis diseases (IB) and Newcastle diseases (ND) at 7 
and 14 days, and infectious bursal diseases (IBD) at 21 days of age through the intraocular route. Feed and water were supplied ad-libitum throughout the experimental period. The lighting system and room temperature were followed according to the commercial recommendations. The room temperature was $35^{\circ} \mathrm{C}$ at first week, then reduced to $28^{\circ} \mathrm{C}$ till finished of the experiment. The light was provided $22 \mathrm{~h}$ during the first week then decreased to $16 \mathrm{~h}$ up to the end of experiment.

The basal diet composed of corn and soybean with four levels of oil combinations: palm oil (PO), a saturated fat by sunflower oil (SO) unsaturated fat. The dietary treatments were $\mathrm{T} 1$, basal diet containing 6\% PO (control); T2, basal diet containing 4\% PO + $2 \% \mathrm{SO} ; \mathrm{T} 3$, basal diet containing $2 \% \mathrm{PO}+4 \% \mathrm{SO}$; and $\mathrm{T} 4$, basal diet containing $6 \%$ SO. Palm oil commonly used as dietary oil source in poultry in Malaysia, thus it was used as control in this experiment. All diets were iso-caloric and iso-nitrogenous and formulated according to the nutrient requirements of broiler by using FeedLIVE software (FeedLIVE 1.52.Thailand).

The ingredients and nutrient composition of starter and finisher diet were fed the birds according to Khatun et al. (2017). Feed intake per replicate and body weight of individual birds were recorded weekly. Average daily weight gain, feed conversion ratio (FCR) was then calculated. The 6 broilers per treatments were slaughtered at 6 weeks of age and breast muscle and liver sample were collected and was snapped frozen in liquid nitrogen and stored at $-80^{\circ} \mathrm{C}$. The samples were used to measure cholesterol content of meat and fatty acid profile of liver.

The fatty acid composition of liver tissue samples were analyzed according to the method [11], as described [3], by using chloroform: methanol 2:1(v/v). Fourteen percent methanolic boron trifluoride (BF3) (Sigma Chemical Co., St. Lous, Mo, USA) and $0.66 \mathrm{~N} \mathrm{KOH}$ in methanol were used to trans methylation of the extracted fatty acid to their fatty acid methyl esters (FAME) according to the method [12]. The heneicosanoic acid (C21:0, Sigma Co., St Louis, MI, USA) was used as internal standard to each sample prior to transmethylation. The detector temperature was programmed at $300^{\circ} \mathrm{C}$ and injector temperature was at $250^{\circ} \mathrm{C}$. The FA concentrations were expressed as percentage of total identified fatty acid and concentration of monounsaturated fatty acid (MUFA), PUFA, unsaturated fatty acid (UFA) and SFA were determined from this value PUFA:SFA and UFA:SFA ratios were calculated.

The meat cholesterol was determined using the method [13]. About one gram crushed sample was homogenized with $2 \mathrm{~mL}$ $50 \%(\mathrm{w} / \mathrm{v})$ potassium hydroxide and $3 \mathrm{~mL} \mathrm{95 \%} \mathrm{ethanol} \mathrm{and}$ incubated at $60^{\circ} \mathrm{C}$ in a water bath for $10 \mathrm{~min}$ and followed by cooling at room temperature. After that $3 \mathrm{ml}$ deionized water and $5 \mathrm{~mL}$ hexane were mixed with the homogenates then vortex for $20 \mathrm{~s}$ and kept in room temperature for 15 minutes in order to complete phase separation. About $2.5 \mathrm{~mL}$ hexane (upper phase) was taken and transferred into a clean test tube and dried by evaporating using nitrogen gas flow at temperature $60^{\circ} \mathrm{C}$. The dried residue was re-suspended using $4 \mathrm{~mL}$ o-phthalaldehyde reagent and kept 10 minutes at room temperature.

After that $2 \mathrm{~mL}$ concentrated sulphuric acid were added slowly into the tube and mixed properly and stand in room temperature further 10 minutes. Cholesterol standards (Sigma L-4646) were prepared at concentrations of $0,10,20,30,40,50,60,70,80,90$, and $100 \mu \mathrm{g}$ cholesterol $/ \mathrm{mL}$. The absorbance of samples and standard were read using spectrophotometer (Secomam, Domont, France) at $550 \mathrm{~nm}$ and cholesterol concentration was calculated using the standard curve.

The experiment was conducted following completely randomized design (CRD). All data were analyzed using the generalized linear model (GLM) of SAS14 (SAS, 2007). The significant mean differences were separated using the Duncan multiple range test (DMRT) at significant level of $\mathrm{P}<0.05$.

\section{Results and Discussion}

The body weight and feed intake of broilers fed different sources of oil are presented in Table 1 . The result reveals that the body weight gain increased and feed conversion ratio (FCR) decreased with the increasing level of unsaturated fatty acid sources oil (SO) compared to control group $(\mathrm{PO})$. Significantly higher $(\mathrm{P}<0.05)$ daily body weight gain and lower FCR were found in broilers fed dietary treatments $\mathrm{T} 3(2 \% \mathrm{PO}+4 \% \mathrm{SO})$ both at 1 to 3 weeks and 1 to 6 weeks (overall), whereas no significant differences were observed at 4 to 6 weeks. No differences $(\mathrm{P}<0.05)$ were also found in daily body weight gain and FCR among the dietary treatments containing two types of oil and SO alone. The overall higher daily weight gain in broilers fed $\mathrm{SO}$ and combination of $\mathrm{PO}$ and SO corroborates with the findings [15], who observed improved feed efficiency in birds fed diet supplemented SO compared to the birds fed PO diets. The improvement of feed efficiency in SO and combination of SO and PO diets might be due to the higher amount of unsaturated fatty acid content in this dietary group, which are more soluble into micells and attributed to increased digestibility of diet containing unsaturated fat than saturated fats. In contrast, work previously reported [16] no significant difference for growth performance in birds supplemented with sunflower oil, linseed oil and soybean oil. Dietary fat sources had no effect on feed intake of birds for the whole experimental periods. Current study agrees with the report $[17,18]$, who claimed that feed intake was not influenced by addition of different sources of dietary fats in broiler.

Dietary supplementation different types of fats influence the fatty acid composition of liver. Major fatty acids were affected by dietary treatment comprised C16:0, C18:1n-9, C18:2n-6 (Table 2). Increasing the dietary SO decreased the level of C16:0, C18:0, C18:1n-9, SFA and MUFA and increased the C18:2n-6, UFA: PUFA, UFA: SFA and PUFA: SFA. However, bird fed combination of SO and PO (T2 and T3) had the intermediate levels of SFA, MUFA, UFA: SFA and PUFA: SFA compare to bird fed only with PO (T1) and SO (T4). The concentration of palmitic acid (C16:0), well as SFA content in liver were higher in chicken fed PO compared to those fed other dietary treatments.

Table 1: Effect of different sources of fat on growth performance of broiler

\begin{tabular}{|c|c|c|c|c|c|}
\hline \multirow[t]{2}{*}{ Parameter } & \multicolumn{4}{|c|}{ Treatments* } & \multirow[t]{2}{*}{ SEM } \\
\hline & $\mathrm{T}_{1}$ & $\mathrm{~T}_{2}$ & $\mathrm{~T}_{3}$ & $\mathrm{~T}_{4}$ & \\
\hline \multicolumn{6}{|c|}{ Average daily weight gain (g/d) } \\
\hline Week 1-3 & $30.19^{b}$ & $31.95^{\mathrm{ab}}$ & $33.20^{\mathrm{a}}$ & $32.86^{\mathrm{a}}$ & 0.414 \\
\hline Week 4-6 & 69.28 & 71.79 & 73.56 & 73.73 & 0.751 \\
\hline Overall & $49.73^{\mathrm{b}}$ & $51.87^{\mathrm{ab}}$ & $53.38^{\mathrm{a}}$ & $53.32^{\mathrm{a}}$ & 0.473 \\
\hline \multicolumn{6}{|c|}{ Feed intake $(g / d)$} \\
\hline Week 1-3 & 50.94 & 50.72 & 49.99 & 50.41 & 0.484 \\
\hline Week 4-6 & 120.51 & 121.02 & 121.49 & 121.9 & 0.923 \\
\hline Overall & 85.73 & 86.33 & 85.74 & 85.71 & 0.499 \\
\hline \multicolumn{6}{|c|}{ Feed conversion ratio } \\
\hline Week 3 & $1.68^{\mathrm{a}}$ & $1.59^{\mathrm{b}}$ & $1.51^{\mathrm{b}}$ & $1.54^{\mathrm{b}}$ & 0.206 \\
\hline Week 6 & 1.74 & 1.70 & 1.66 & 1.64 & 0.02 \\
\hline Overall & $1.71^{\mathrm{a}}$ & $1.67^{\mathrm{ab}}$ & $1.61^{\mathrm{a}}$ & $1.61^{\mathrm{a}}$ & 0.015 \\
\hline
\end{tabular}
significantly $(\mathrm{p}<0.05)$

* $\mathrm{T}_{1}: 6 \%$ palm oil (control), $\mathrm{T}_{2}:\left(4 \%\right.$ palm oil $+2 \%$ sunflower oil, $\mathrm{T}_{3}$ : (2\% palm oil $+4 \%$

sunflower oil), $\mathrm{T}_{4}:(6 \%$ Sunflower oil). 
These findings agree with the findings [9], who observed higher level of SFA in liver of broiler fed palm oil (PO) than sunflower oil (SO).

The bird fed PO diet had significantly higher proportion of palmitic and oleic acids might be owing to

the high palmitic and oleic acid content of palm oil. In addition, the birds fed SO and combination of SO and PO diets had higher proportion of linoleic acid (C18:2n-6) compared to birds fed PO due to higher concentration of linoleic acid present in SO diets. Moreover, concentration of monounsaturated fatty acids (MUFA) especially C18:1n-9 was lower for the SO and combination of SO and $\mathrm{PO}$ group in the liver, it would appear that increasing contents of C18:2 decrease the desaturation of saturated fatty acids into MUFA. This observation concurs with the findings[19, 9], who reported lower synthesis rate of MUFA in pigs and chicken fed with a SO diet as compared with beef tallow and palm oil, respectively. Cholesterol plays an important function as a precursor for the synthesis of vitamin D, steroid hormones, and bile acids, as well as component of cell membrane [2]. However, higher intake of cholesterol through diet highly related with arteriosclerosis and coronary heart disease $[8,20]$. Moreover, previous study has been reported [21] a strong association between Alzheimer's disease and concentration of cellular cholesterol. The meat cholesterol content of broilers fed different sources of dietary fats as shown in Fig 1. The birds fed PO had higher cholesterol concentration in meat which was decreased by supplementation of unsaturated fatty acid sources oil (SO) in broiler diet. However, no differences were found in cholesterol concentration in meat among the dietary SO and combination of SO and PO. Higher level of cholesterol content in meat may be related with higher level of hepatic SFA and lower level of UFA concentration of birds fed PO dietary group compared to other groups. In addition, higher ratio of PUFA/SFA in birds fed SO and combination of SO and PO might be another cause of lower concentration of cholesterol in meat. This assertion corroborates the previous observation $[18,22]$ of, who reported broiler fed with diet containing higher concentration of UFA compared to SFA reduced the cholesterol level in breast muscle. Similar result was also reported [3], who observed higher $(\mathrm{P}<0.05)$ level of cholesterol content in breast muscle when broiler fed diet containing palm oil compared to those fed linseed oil and soybean oil.

Table 2: Fatty acid composition (\% of total identified fatty acids) of liver tissue in broiler chicken fed different sources of oil

\begin{tabular}{|c|c|c|c|c|c|}
\hline \multirow[t]{2}{*}{ Fatty acid (\%) } & \multicolumn{4}{|c|}{ Treatments* } & \multirow[t]{2}{*}{$\mathrm{SEM}^{5}$} \\
\hline & $\mathrm{T}_{1}$ & $T_{2}$ & $\mathrm{~T}_{3}$ & $\mathrm{~T}_{4}$ & \\
\hline C14:0 & $0.33^{\mathrm{b}}$ & $0.50^{\mathrm{a}}$ & $0.51^{\mathrm{a}}$ & $0.54^{\mathrm{a}}$ & 0.027 \\
\hline C16:0 & $26.22^{\mathrm{a}}$ & $23.01^{\mathrm{b}}$ & $21.18^{\mathrm{bc}}$ & $19.29^{c}$ & 0.740 \\
\hline C16:1 & 3.71 & 2.43 & 2.69 & 2.24 & 0.269 \\
\hline C18:0 & 16.91 & 16.02 & 15.98 & 15.73 & 0.652 \\
\hline C18:1n-9 & $32.58^{\mathrm{a}}$ & $32.31^{\mathrm{a}}$ & $28.95^{\mathrm{ab}}$ & $27.63^{\mathrm{b}}$ & 0.785 \\
\hline C18:2n-6 & $14.27^{\mathrm{d}}$ & $18.78^{\mathrm{c}}$ & $23.52^{\mathrm{b}}$ & $26.94^{\mathrm{a}}$ & 1.299 \\
\hline C18:3n-3 & $0.53^{\mathrm{b}}$ & $0.72^{\mathrm{a}}$ & $0.80^{\mathrm{a}}$ & $0.87^{\mathrm{a}}$ & 0.040 \\
\hline C20:4n-6 & $3.99^{\mathrm{a}}$ & $4.53^{\mathrm{a}}$ & $4.59^{\mathrm{a}}$ & $5.02^{\mathrm{a}}$ & 0.207 \\
\hline C20:5n-3 & $0.24^{\mathrm{b}}$ & $0.35^{\mathrm{a}}$ & $0.37^{\mathrm{a}}$ & $0.41^{\mathrm{a}}$ & 0.211 \\
\hline$C 22: 5 n-3$ & $0.37^{\mathrm{c}}$ & $0.59^{\mathrm{b}}$ & $0.65^{\mathrm{ab}}$ & $0.78^{\mathrm{a}}$ & 0.044 \\
\hline C22:6n-3 & 0.63 & 0.73 & 0.74 & 0.77 & 0.024 \\
\hline SFA $^{1}$ & $43.67^{\mathrm{a}}$ & $39.53^{\mathrm{b}}$ & $37.66^{\mathrm{bc}}$ & $35.35^{\mathrm{c}}$ & 0.958 \\
\hline $\mathrm{UFA}^{2}$ & $56.33^{\mathrm{c}}$ & $60.47^{\mathrm{b}}$ & $60.34^{\mathrm{ab}}$ & $60.65^{\mathrm{a}}$ & 0.958 \\
\hline MUFA $^{3}$ & $36.29^{\mathrm{a}}$ & $34.74^{\mathrm{a}}$ & $31.64^{\mathrm{ab}}$ & $29.87^{\mathrm{b}}$ & 0.929 \\
\hline PUFA $^{4}$ & $20.04^{\mathrm{d}}$ & $25.73^{\mathrm{c}}$ & $30.70^{\mathrm{b}}$ & $34.77^{\mathrm{a}}$ & 1.50 \\
\hline UFA:SFA & $1.29^{\mathrm{c}}$ & $1.53^{\mathrm{b}}$ & $1.68^{\mathrm{ab}}$ & $1.83^{\mathrm{a}}$ & 0.065 \\
\hline PUFA:SFA & $0.46^{\mathrm{d}}$ & $0.65^{\mathrm{c}}$ & $0.82^{\mathrm{b}}$ & $0.99^{\mathrm{a}}$ & 0.054 \\
\hline
\end{tabular}

${ }^{\mathrm{a}, \mathrm{b}, \mathrm{c}}$ Means with different superscript in the same row differ significantly $(\mathrm{P}<0.05)$.

* T1: $6 \%$ PO (control), T2: $4 \% \mathrm{PO}+2 \% \mathrm{SO}, \mathrm{T} 3: 2 \% \mathrm{PO}+4 \%$

SO, T4: $6 \%$ SO. ${ }^{1}$ Total saturated fatty acid=sum of

C14:0+C16:0+C18:0, ${ }^{2}$ Total unsaturated fatty acid $=$ sum of

C16:1+C18:1n-9 + C18:2n-6 + C18:3n-3+C20:4n-6 + C20:5n-

$3+\mathrm{C} 22: 5 \mathrm{n}-3$

${ }^{3}$ Total monounsaturated fatty acid=sum of C16:1+C18:1n-9
${ }^{4}$ Total polyunsaturated fatty acid=sum of C18:2n-6 + C18:3n-3 + C20:4n-6 + C20:5n-3+ C22:5n-3

${ }^{5} \mathrm{SEM}=$ standard error of means.

Cholesterol plays an important function as a precursor for the synthesis of vitamin D, steroid hormones, and bile acids, as well as component of cell membrane [2]. However, higher intake of cholesterol through diet highly related with arteriosclerosis and coronary heart disease $[8,20]$. Moreover, previous work has been reported $^{22}$ a strong association between Alzheimer's disease and concentration of cellular cholesterol. The meat cholesterol content of broilers fed different sources of dietary fats as shown in Fig 1. The birds fed PO had higher cholesterol concentration in meat which was decreased by supplementation of unsaturated fatty acid sources oil (SO) in broiler diet. However, no differences were found in cholesterol concentration in meat among the dietary SO and combination of SO and PO. Higher level of cholesterol content in meat may be related with higher level of hepatic SFA and lower level of UFA concentration of birds fed PO dietary group compared to other groups (Table 2). In addition, higher ratio of PUFA/SFA in birds fed SO and combination of SO and PO might be another cause of lower concentration of cholesterol in meat. This assertion corroborates the observation $[18,22]$, who reported broiler fed with diet containing higher concentration of UFA compared to SFA reduced the cholesterol level in breast muscle. Similar result was also reported, ${ }^{3}$ who observed higher $(\mathrm{P}<0.05)$ level of cholesterol content in breast muscle when broiler fed diet containing palm oil compared to those fed linseed oil and soybean oil.

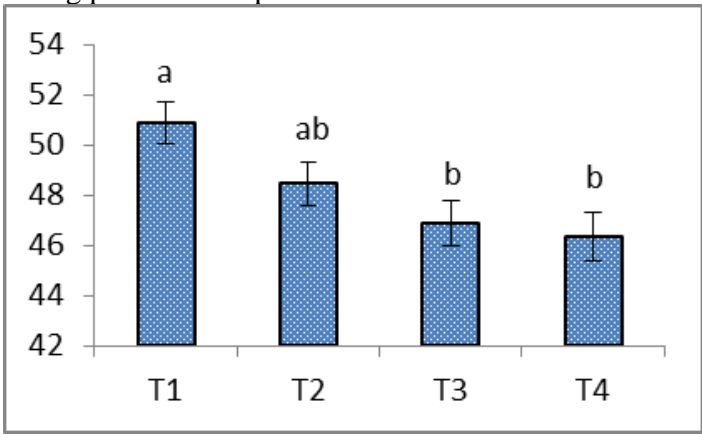

Figure 1: Cholesterol concentration of broiler breast muscle fed different sources of dietary fats.

\section{Conclusion}

The results of this study indicated that supplementation of SO with combination of PO increased the daily gain and reduced FCR of broiler. Furthermore, fatty acid composition of broiler liver was modified to varying degree by the types of dietary fat. The concentration of total UFA, PUFA: SFA and UFA: SFA increased and total SFA and MUFA decreased by inclusion of increasing levels of SO in broilers diets. The combination of SO and PO and SO alone reduced concentration of MUFA in liver indicates a reduction of de novo synthesis of fatty acid in these group. Moreover, the birds fed PO observed higher meat cholesterol content as compared with SO and combination of SO and PO. However, no differences were observed of broiler in overall performance and meat cholesterol content among the two types of oil combination and $\mathrm{SO}$ alone. Hence, considering the availability and cost of PO the combination of PO and SO in broiler diet seemed to be beneficial for better performance and improve meat quality by decreasing the cholesterol content in meat.

\section{Acknowledgement}

The research fund was supported by the Long-Term Research Grant Scheme (LRGS) from the Ministry of Education Malaysia. The authors are also grateful to the Organization for Women in Science and Technology for the Developing World (OWSD), Trieste, Italy for providing the $\mathrm{PhD}$ Fellowship to the first author. 


\section{References}

[1] Baião, N.C and Lara, L., Oil and fat in broiler Nutrition. Revista Brasileira de Cliencia Avicola, 2005. 7: p.129

[2] Chwen, L.T. et al., Growth performance, plasma fattyacids, villous height and crypt depth of pre-weaning piglets fed with medium chain triacylglycerol. Asian-Australasian Journal of Animal Science, 2013. 26: 5

[3] Abdulla, N.R. et al., Fatty acid profile, cholesterol and oxidative status in broiler chicken breast muscle fed different dietary oil sources and calcium levels. South African Journal of Animal Sciences, 2015. 45: p.153-163.

[4] Khatun, J. et al., Fatty acid composition, fat deposition, lipogenic gene expression and performance of broiler fed diet supplemented with different sources of oil. Animal Science Journal, 2017. 88:

[5] Viveros, A. et al., Interaction of dietary high-oleic acid sunflowe hulls and different fat sources in broiler chickens. Poultry Science, 2009, 88: p. 141-151.

[6] Aghwan, Z. et al., Fatty acid profiles of supraspinatus, longissimuslumborum and semitendinosus muscles and serum in kacang goats supplemented with inorganic selenium and iodine. Asian- Australasian Journal of Animal Science, 2014, 27: p. 543-550.

[7] Sacks, F.M., The role of high-density lipoprotein (HDL) cholesterol in the prevention and treatment of coronary heart disease: expert group recommendations. American Journal of Cardiology, 2002, 90: p. 139-143.

[8] Houston, D.K. et al., Dietary fat and cholesterol and risk of cardiovascular disease in older adults: the Health ABC Study. Nutrition, Metabolism and Cardiovascular Diseases, 2011. 21: p. 430-7.

[9] Smink, W. et al., Effect of dietary fat sources on fatty acid deposition and lipid metabolism in broiler chickens. Poultry Sci.ence, 2010. 89: p. 2432-2440.

[10] Adeyemi, K. and Olorunsanya, A. Effect of tomato (Lycopersiconesculentum) powder on oxidative stability and sensory characteristics of broiler meat. African Journal of Food, Agriculture andNutrition Development, 2012.12: p. 6794-6808.

[11] Folch, J. et al., A simple method for the isolation and purification of total lipids from animal tissues. Journal of Biological Chemistry, 1957. 226: p.497-509.

[12] AOAC. 1990.Official Methods of Analysis.15th ed. Association of Official Analytical Chemists. Ed: Herlick, K., Arlington, VA, USA, 1990. P.1230.

[13] Rudel, L. and Morris, M., Determination of cholesterol using ophthalaldehyde. Journal of Lipid Research,1973. 14: p. 364-366

[14] SAS, 2007. User's Guide. 9.2 ed. In SAS institute, Inc., Cary, NC, USA

[15] Velasco, S. et al., Effect of inulin supplementation and dietary fat source on performance, blood serum metabolites, liver lipids, abdominal fat deposition, and tissue fatty acid composition in broiler chickens. Poultry Science, 2010. 89: p.1651-1662.

[16] Fébel, H. et al., Effect of dietary fatty acid pattern on growth, body fat composition and antioxidant parameters in broilers. Journal of Animal Physiololy, Animal Nutrition , 2008. 92: p. 369-376

[17] Abdulla, N.R. et al., Effects of dietary oil sources, calcium and phosphorus levels on growth performance, carcass characteristics and bone quality of broiler chickens. Journal of Applied Animal Research, 2017. 45(1).

[18] Azman, M. et al., Effects of different dietary fat sources on growth performances and carcass fatty acid composition of broiler chickens Seven, Revue de Médecine Vétérinaire,2004. 155 : p.278-286

[19] Mitchaothai, J. et al., Digestion and deposition of individual fatty acidsin growing-finishing pigs fed diets containing either beef tallow. Beynen, Journal Animal Physiology Animal Nutrition (Berl), 2008. 92(4).

[20] Larsson, S.C. et al., Dietary fats and dietary cholesteroland risk of stroke in women. Atherosclerosis, 2012. 221:p.282-6

[21] Michikawa, M. et al., The role of cholesterol in pathogenesis of Alzheimer's disease. Molecular Neurobiology, 2003.27: p.1-12

[22] Duraisamy, K. et al., Effect of saturated and unsaturated fat on the performance, serum and meat cholesterol level in broilers. Veterinary World, 2013. 6: p.159-162. 